\title{
Hyperpigmentation in North Sea dab Limanda limanda. II. Macroscopic and microscopic characteristics and pathogen screening
}

\author{
P. A. Noguera ${ }^{1, *}$, S. W. Feist ${ }^{2}$, K. S. Bateman ${ }^{2}$, T. Lang ${ }^{3}$, F. Grütjen ${ }^{3}$, D. W. Bruno ${ }^{1}$ \\ ${ }^{1}$ Marine Scotland Science, 375 Victoria Road, Aberdeen AB11 9DB, UK \\ ${ }^{2}$ Cefas Weymouth Laboratory, Barrack Road, Weymouth DT4 8UB, UK \\ ${ }^{3}$ Thünen Institute of Fisheries Ecology, Deichstr. 12, 27472 Cuxhaven, Germany
}

\begin{abstract}
An increasing trend in the prevalence of hyperpigmentation in the common dab Limanda limanda from the North Sea prompted us to investigate the potential role of infectious agents as causes or contributing factors to the condition. Dab representing 3 severity grades of hyperpigmentation were sampled for virology, bacteriology, histopathology and ultrastructure assessments. No cytopathic effect was recorded during virology testing, and bacteriological results showed no differences between normal and hyperpigmented dab. Histopathological assessment showed that the most significant changes occurred in the dermis as a result of chromatophore hyperplasia, namely melanophores and iridophores, alongside loose melanin granules. Dermal lymphocytic infiltration occasionally expanding into the epidermis and the underlying musculature was more frequent in highly pigmented dab than in normal fish, suggesting an active immune response. Ultrastructure studies showed additional disruption of the epithelial layer, with loose melanin granules between cells and a number of single or aggregated melanocytes. Dab representing different grades of hyperpigmentation kept in the laboratory alongside normal fish for a monitoring period of 18 mo showed no changes in their pigment distribution pattern, nor occurrence of new pigment in the normal fish. The current investigation found no association of hyperpigmentation in the common dab with infectious agents; therefore, understanding the cause of the condition remains a challenge which can now more reliably focus on a non-infectious origin hypothesis.
\end{abstract}

KEY WORDS: Common dab · Flatfish $\cdot$ Pigment anomaly $\cdot$ Chromatophores $\cdot$ Hyperplasia

\section{INTRODUCTION}

Common dab Limanda limanda are widespread in the North Sea and live in direct contact with sediments. Consequently, dab have been used as an important sentinel species for assessing biological effects of contaminants in international and national monitoring programmes such as the UK Clean Seas Environmental Monitoring Programme (Lyons et al. 2010). Selected diseases of common dab from the North Sea and adjacent areas have been monitored on a regular basis by laboratories in Germany, Denmark, The Netherlands and the
UK, using methodologies according to the International Council for the Exploration of the Sea (ICES) standard guidelines (Bucke et al. 1996, Lang 2002). Several macroscopic external conditions are recorded, including skin ulcers, lymphocystis and epidermal hyperplasia/papilloma, as well as hyperpigmentation. In combination with the occurrence of parasites and the presence of contaminantrelated liver pathology, an overall assessment is made of the health status of individual fish and in combination for the population at particular sites (McVicar et al. 1988, Lang \& Wosniok 2008, Stentiford et al. 2009). 
In the UK, annual long-term health monitoring surveys of common dab have been conducted since the 1980s by Marine Scotland Science (formerly Fisheries Research Services) and the Centre for Environment, Fisheries \& Aquaculture Science. Data on hyperpigmentation have been collected since 1989 and recorded against 3 grades of severity. Similarly, studies in other areas of the North Sea have demonstrated that prevalence levels of hyperpigmentation of common dab populations have also risen and have provided information on statistical analysis of the spatial and temporal patterns of the condition, suggesting a tendency for lower condition factor, particularly among fish in the highest severity grade (Grütjen et al. 2013, this issue)

Hyperpigmentation is defined as the occurrence of spots or diffuse patches of green to black pigment on the ocular side, and occasionally, pearly-white spots on the abocular side. This is different from pleuronectid pigment abnormalities that have been described since the late 1800s, including the development of pigment on the underside under experimental conditions (Cunningham \& MacMunn 1893), or ambicolouration as reported in winter flounder Pseudopleuronectes americanus (Gudger 1934) and Atlantic halibut Hippoglossus hippoglossus (Burton 1988).

Despite an apparent increase in the occurrence of hyperpigmentation, no investigation has been carried out to identify or rule out whether infectious agents play a role in the presence and the increasing prevalence of the condition. We examined the potential involvement of infectious organisms in association with or directly causing hyperpigmentation. The histopathology and ultrastructure of the changes are described, and other potential non-infectious origins are discussed (ontogenic disturbance, UV radiation, nutrition and environmental factors). Grütjen et al. (2013) provide information on spatial and temporal characteristics of the phenomenon in the North Sea and adjacent areas.

\section{MATERIALS AND METHODS}

\section{Sampling}

Fish were collected during a disease monitoring survey in the northern North Sea in late May to June 2007 using RV 'Scotia III'. One hour trawls with a BT101 (48' [ 14.8 m] Aberdeen trawl) were used at each of 6 stations: Moray Firth (nominal centre $58^{\circ} 08.0^{\prime} \mathrm{N}, 03^{\circ} 01.0^{\prime} \mathrm{W}$ ), southeast of Fair
Isle $\left(59^{\circ} 13.0^{\prime} \mathrm{N}, 01^{\circ} 30.0^{\prime} \mathrm{W}\right)$, Bell Rock $\left(56^{\circ} 25.5^{\prime} \mathrm{N}\right.$,

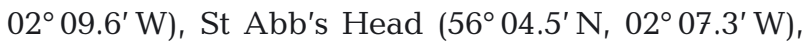
Wee Bankie $\left(56^{\circ} 16.25^{\prime} \mathrm{N}, 02^{\circ} 06.25^{\prime} \mathrm{W}\right)$ and Marr Bank $\left(56^{\circ} 25.0^{\prime} \mathrm{N}, 01^{\circ} 50.0^{\prime} \mathrm{W}\right)$. After the total catch was sorted by species, a process that took approximately $1 \mathrm{~h}$, all common dab were sexed by the shape of the gonads, but if there was any doubt, sex allocation was verified through dissection. Total length was rounded down to the nearest $\mathrm{cm}$, and external signs of disease were recorded using international methodology as specified by the ICES (Bucke et al. 1996). Staff members were trained to an agreed level of competence, and selected fish for this study were rechecked by the most experienced staff member to limit any bias due to inter-observer variability. Fish displaying hyperpigmentation were sorted into 3 groups representing the different severity grades (Fig. 1; described in Grütjen et al. 2013), based on the number and spread of pigment spots on the ocular side according to the Biological Effects Quality Assurance Monitoring Programme (BEQUALM; www.bequalm.org).

A sub-sample totalling $72 \mathrm{dab}$, which included 9 hyperpigmented (3 per category) plus 3 normal pigmented fish from each station, were subjected to a complete necropsy for gross examination and bacteriological, virological and histological sampling. For
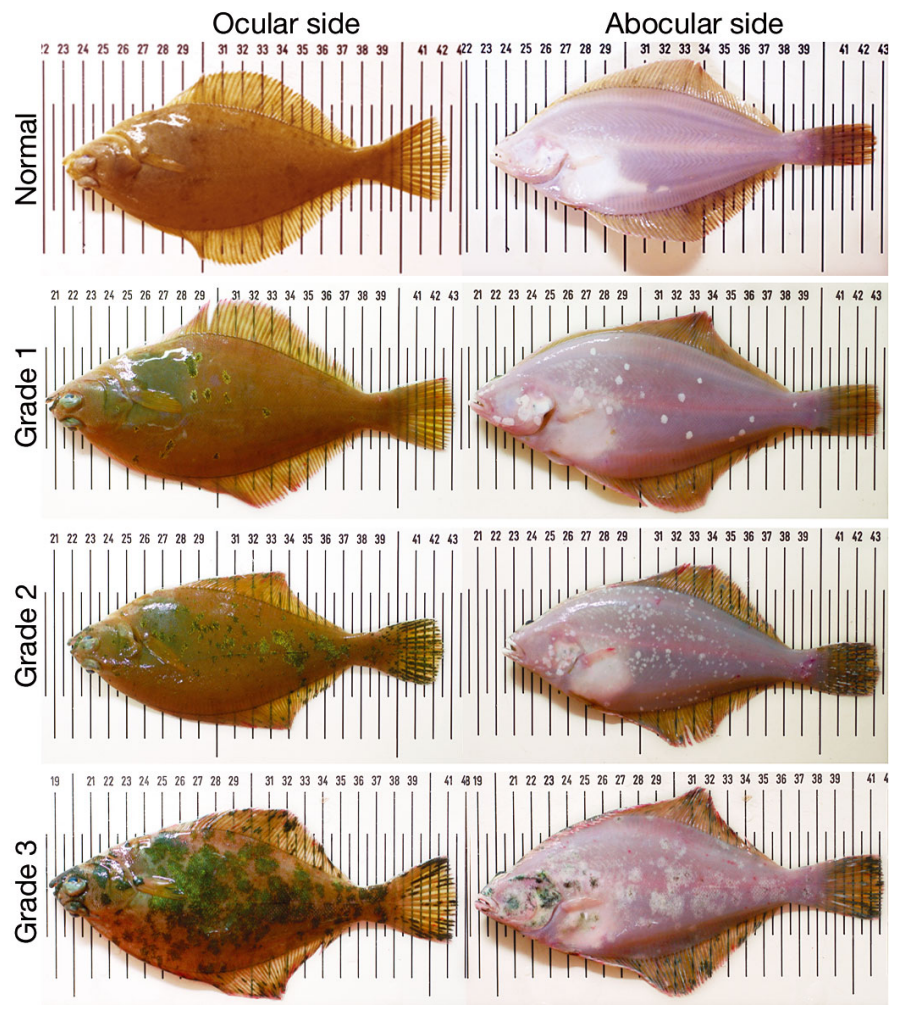

Fig. 1. Limanda limanda. Examples of common dab representing hyperpigmentation grades 1,2 and 3 
consistency reasons, all samples were taken from female fish measuring 20 to $24 \mathrm{~cm}$. Additionally, 9 samples from selected individuals were made available for external disease assessment, liver pathology and for histological and ultrastructural analysis, from the North Sea north east Dogger Bank (nominal centre $55^{\circ} 16.0^{\prime} \mathrm{N}, 02^{\circ} 54.1^{\prime} \mathrm{E}$ ) and north Dogger Bank (nominal centre $55^{\circ} 03.0^{\prime} \mathrm{N}, 02^{\circ} 03.5^{\prime} \mathrm{E}$ ) collected during a 2006 cruise.

\section{Bacteriology}

Fish skin was swabbed with $70 \%$ ethanol, and samples were taken aseptically from directly underneath the skin surface and internally from the kidney. They were inoculated onto tryptic soy agar plates with $2 \% \mathrm{NaCl}$ and incubated at $15^{\circ} \mathrm{C}$. In the laboratory, plates were examined daily for bacterial growth for up to $2 \mathrm{wk}$, and significant colonies were examined biochemically including the standardized identification system API 20E (bioMérieux).

\section{Virology}

A total of 1296 individual samples were taken to the laboratory for analysis by virus culture. They represented individual samples of liver, muscle-skin and gill from each fish which were either snap frozen in liquid nitrogen (from the stations sampled early during the trip) or placed directly into virus transport media (samples collected on the last day at sea). Routine diagnostic virus culture was performed. In brief, tissues were homogenised with $9 \mathrm{ml}$ DMEM/20\% serum, stored at $4^{\circ} \mathrm{C}$ and centrifuged at $1900 \times g$ (15 min). Twenty $\mu \mathrm{l}$ of fluid from the homogenate were inoculated into $2 \mathrm{ml}$ of EMEM-10\% foetal bovine serum, $1 \% 200 \mathrm{mM} \mathrm{L}$-glutamine. Six different cell lines were examined for evidence of virus: TV-I, turbot tail fin; FFN, flounder fin; TO, salmon head kidney leucocytes; BF-2, bluegill fibroblast; CHSE214, Chinook salmon embryo; and SBL, sea bass larvae. Each sample was processed individually and passed 2 or 3 times on all cell lines and examined regularly for up to $10 \mathrm{wk}$. Incubation was performed at $15^{\circ} \mathrm{C}$ in a dark environment.

\section{Histology}

Tissues including gills, skin, liver, spleen, kidney, gonad, heart, intestine and brain were taken from all sampled individuals and represented both the 3 levels of pigmentation and normal fish. Tissues were fixed in $10 \%$ neutral buffered formalin, subsequently embedded in paraffin and processed for light microscopy. Sections were cut at $3 \mu \mathrm{m}$, stained with Harris haematoxylin and eosin (H\&E) and analysed under an Olympus BX 60 microscope.

Archived histology samples from the North Sea collected during 2006 at the north east and north Dogger Bank were also re-assessed. The tissues were fixed in the same manner as indicated above. A total of 9 individuals showing the 3 grades of hyperpigmentation were examined. Digital images of representative pathology were taken using a Nikon Eclipse E800 and Lucia ${ }^{\mathrm{TM}}$ Screen Measurement System (Nikon).

\section{Transmission electron microscopy}

For electron microscopy, $2 \mathrm{~mm}^{3}$ blocks of skin tissue from a single dab showing grade 1 hyperpigmentation, 2 fish with grade 2 and 3 individuals with grade 3 were fixed in a solution containing $2.5 \%$ glutaraldehyde in $0.1 \mathrm{M}$ sodium cacodylate buffer ( $\mathrm{pH} 7.4$ ) for $2 \mathrm{~h}$ at room temperature. Fixed tissue samples were rinsed in $0.1 \mathrm{M}$ sodium cacodylate buffer ( $\mathrm{pH} 7.4)$ and post-fixed in $1 \%$ osmium tetroxide in $0.1 \mathrm{M}$ sodium cacodylate buffer for $1 \mathrm{~h}$ at $4^{\circ} \mathrm{C}$. Specimens were washed in 3 changes of $0.1 \mathrm{M}$ sodium cacodylate buffer and dehydrated through an acetone series. Specimens were embedded in Agar 100 epoxy resin (Agar Scientific Agar 100 pre-mix kit medium). Semi-thin sections $(1-2 \mu \mathrm{m})$ were stained with toluidine blue for viewing with a light microscope. Suitable areas were identified, and ultrathin sections $(70-90 \mathrm{~nm})$ of these areas were cut and mounted on uncoated copper grids. Sections were stained with uranyl acetate and Reynolds lead citrate and were examined using JEOL JEM1210 and JEOL JEM 1400 transmission electron microscopes. Images were recorded with an AMT XR80 camera system using AMT Advantage V601 software.

\section{Passive observation experiment}

Mixed-sex dab $(\mathrm{n}=32)$ of $>18 \mathrm{~cm}$ with and without hyperpigmentation were collected right after capture and held in tanks while at sea with constant exchange of sea water in order to keep them alive for a time course study. The fish were moved to the laboratory and divided into 3 groups according to their 
pigmentation level and held in $2 \mathrm{~m}$ diameter tanks with an $80 \mathrm{~cm}$ water depth, totalling a volume of $2.5 \mathrm{~m}^{3}$ per tank; non-hyperpigmented fish were added to each group. A natural source of flowthrough sea water of approximately $500 \mathrm{l} \mathrm{h}^{-1}$ at an average temperature of 7 to $10^{\circ} \mathrm{C}$ was supplied, after being filtered through a re-circulation system. The lighting simulated the natural daylight cycle for the year, combined with a low level of green light, with dawn and dusk cycles. The tanks were provided with a thin layer of sand and were constantly aerated. The dab were fed wet feed (squid, white fish and prawns) on average once every $2 \mathrm{~d}$, and once a week they were given a commercial marine pellet feed. At initiation and approximately bimonthly intervals over a period of $18 \mathrm{mo}$, the sand was siphoned away and the water level reduced to $30 \mathrm{~cm}$. Each fish was photographed in situ, and digital images were used to compare individual fish to assess potential pigment pattern changes.

\section{RESULTS}

\section{Gross examination}

Pigmented spots or areas are normally dark brown to black with frequent fluorescent green spots. Upon anatomical examination, these hyperpigmented areas showed no obvious protrusion from the general surface or a rougher feeling to the touch. Pigment spots on the abocular side, when present, were pearly-white and 'whiter' than the normal nonpigmented blind side background (Fig. 1). Internally, most fish from both hyperpigmented and normal groups had low to moderate loads of parasitic nematodes within the body cavity, particularly on the liver surface or encysted among viscera. Nematodes could also be seen within the liver parenchyma during histological sampling. Other observations included ascites, guts devoid of food and moderate to severe tissue adhesion reactions, occasionally involving the heart.

\section{Histology}

Major differences between normal and hyperpigmented fish were observed in the dermal layer followed by the epidermis. Normal fish showed melanophores, frequently in clusters, as the only obvious chromatophores in the dermal layer, with very few or no granular cells in the epidermis
(Fig. 2). Conversely, architectural distortion was observed in hyperpigmented dab as a result of moderate to severe chromatophore hyperplasia, namely iridophores and non-clustered melanophores with an increase in loose melanin granules (Fig. 3). Dermal melanophores with melanosome dispersion making evident their dendritic extensions and resulting in darkening of the skin, were more frequent in hyperpigmented dab, alongside an increase in epidermal granular cells (Fig. 4). Moreover, melanin-containing cells were observed forming clusters in the epidermal layer in grade 3 dab (Fig. 5), a feature only occasionally recorded in normal pigmented fish. Hyperpigmented fish showed moderate to severe dermal lymphocytic infiltration, sometimes involving the epidermis (Fig. 6, see also Figs. 3 \& 5) and occasionally deeper into the underlying muscle. The characteristic compact multi-layered aspect of the normal epidermis was lost in some of the highly hyperpigmented fish due to a lack of compact cell-tocell attachment and necrosis of Malpighian cells, defining a line of epidermal detachment (Fig. 6). A thickening and lack of clear definition of the basement membrane was evident in the highly pigmented fish (see Figs. 3, 5 \& 6) in comparison with normal fish (see Fig. 2). Occasionally, a complete sloughing of the layer was seen, but due to the catchment method, some mechanically induced erosion cannot be discounted.

Histological observations of the 3 macroscopically defined groups differed only in their level of severity. The underside of affected fish showed mostly intact epithelium with little sloughing and no obvious pigmentation. The colour spots in this surface were mainly comprised of iridophore clusters, and although melanophores were present, their melanosomes were in the compact form. The presence of lymphocytic infiltration in the dermis as described for the upper surface could also occasionally be recorded.

All other tissues were examined, and the nematode larvae observed macroscopically were confirmed histologically on the surface of the liver and pancreas, sometimes associated with an adhesion and inflammatory reaction involving the heart. The atrium consistently showed areas of focal necrosis, with mild to moderate thickening of the endocardium and lymphocytic infiltration, and the latter was sometimes also recorded in the ventricle (images not shown). Overall however, all observations from internal organs were not specifically associated with hyperpigmented fish. 

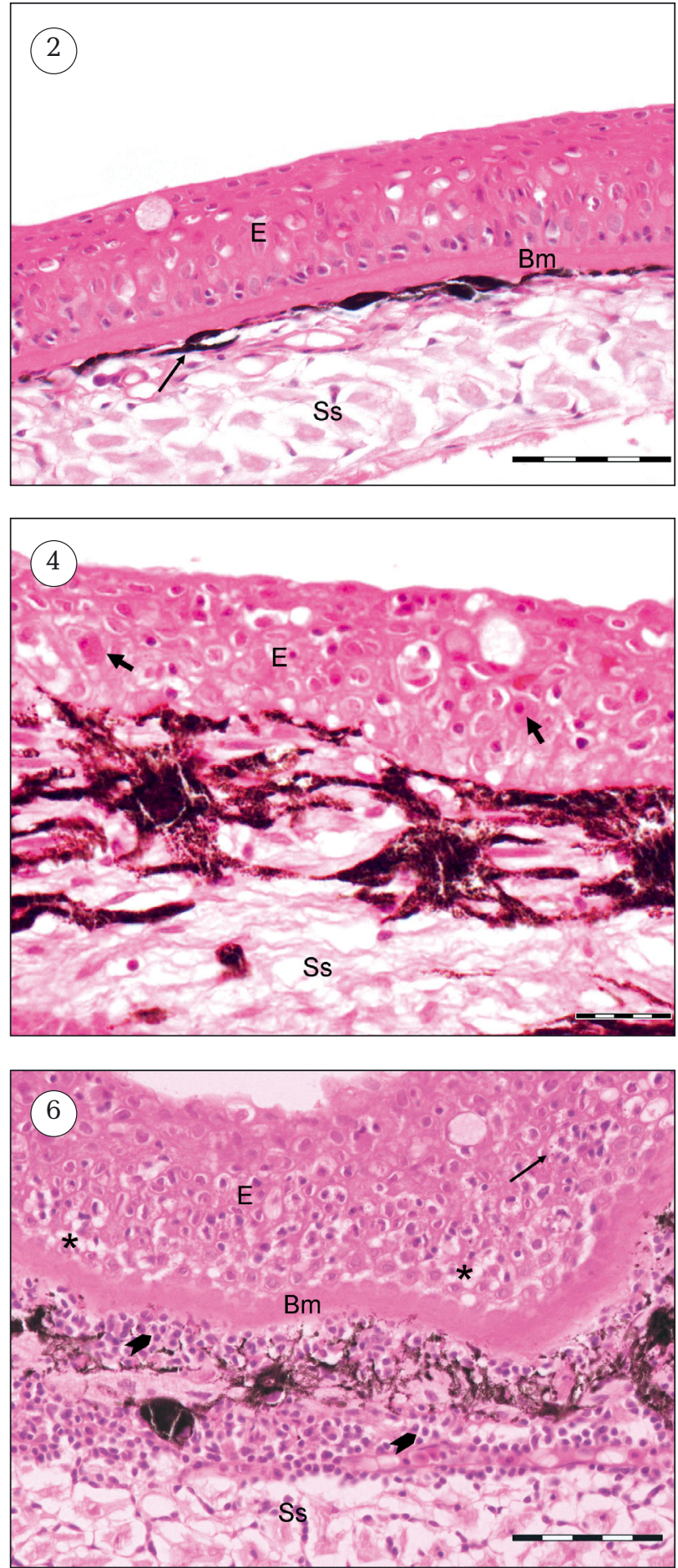

The ultrastructure of the upper surface of hyperpigmented dab showed disruption of the epithelial layer where the normal desmosome connections between epithelial cells were absent, with cells frequently showing loss of normal architecture and necrotic changes. The dermis of severity grade 3 fish showed numerous degenerated iridophores, some
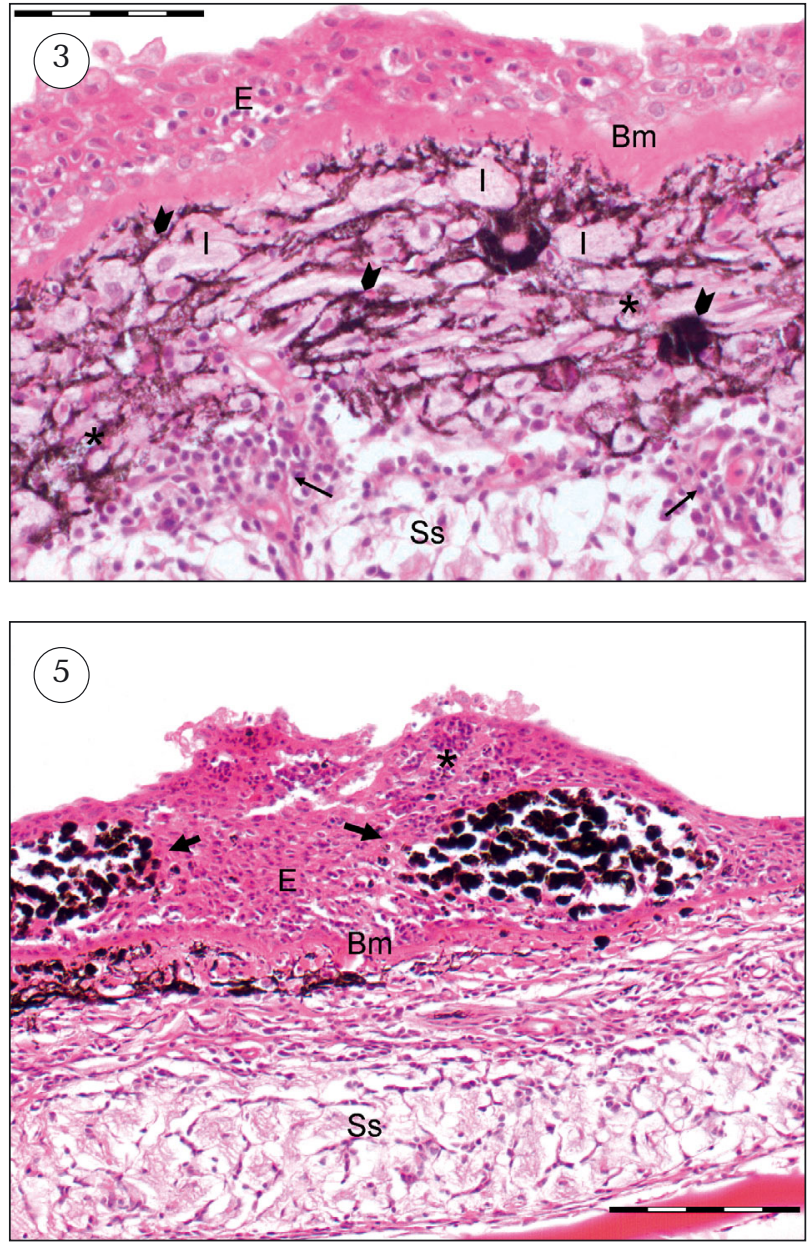

Figs. 2 to 6. Limanda limanda. Upper (ocular) surface skin sections. E: epidermal layer; Ss: stratum spongiosum; Bm: basement membrane; I: iridophores. H\&E staining. Scale bars $=($ Figs. 2 to 4, 6) $50 \mu \mathrm{m}$, (Fig. 5) $100 \mu \mathrm{m}$. Fig. 2. Normal healthy fish. Epidermal and dermal layers are intact. Melanophore (arrows) distribution is characteristically in the upper part of the dermis, and cells are frequently observed in clusters. No obvious iridophores are present. Fig. 3. Architectural distortion in hyperpigmented dab showing moderate to severe hyperplasia of iridophores and non-clustered melanophores (arrowheads). Note also loose melanin granules (*) and lymphocytic infiltration (arrow). Fig. 4. Cytoplasmic melanosome dispersion makes dendritic extensions of melanophores become obvious, and consequently the skin will appear darker. Note also granular cells (arrow) in the epidermis. Fig. 5. Increase in clusters of melanin-containing cells (arrow) in the epidermal layer of hyperpigmented dab. Also note lymphocytic infiltration (*). Fig. 6. Moderate to severe dermal lymphocytic infiltration (arrowheads) and loss of epidermal multi-layered pattern due to a lack of compact cell-to-cell attachment $(*)$ and necrosis (arrow) of Malpi-

ghian cells, defining a line of epidermal detachment

with distortion artefacts in the location previously occupied by guanine crystals (extracted during the processing of the tissue to epoxy resin) and numerous melanin granules dispersed between the irido- 
phores (Fig. 7). We were unable to discern whether they were retained in melanophore dendritic processes or intercellular in location (potentially both). Degenerate cells (possibly macrophages) with numerous mitochondria and large vacuolar structures reminiscent of grossly dilated endoplasmic reticulum were also present throughout the dermis; anchoring fibril structures also appeared degenerated (Fig. 7).

Sections through the epidermis and partly the dermis of the underside of grade 3 fish instead revealed mostly intact architecture, with a defined basal lamina, tight intercellular junctions among the epidermal cells and presence of occasional granulocytes. Dermal iridophores, the most common chomatophore on the underside, were tightly packed together and restricted to the upper layer of the dermis, immediately below the basement membrane which showed intact anchoring fibrils (Fig. 8).

Overall, examination of the ocular and abocular surfaces from normal and hyperpigmented dab showed no evidence of associated micro-organisms by means of light or electron microscopy.

\section{Bacteriology and virology}

Bacteriological examination of skin and kidney resulted in the isolation of 3 types of organisms recorded as type A, B and C both from normal and hyperpigmented fish. All colonies comprised Gram negative rods with growth recorded at 4,15 and $22^{\circ} \mathrm{C}$ but not at $37^{\circ} \mathrm{C}$. Colony type B showed motility and a fermentative reaction, was oxidase- and catalasepositive and was identified as Vibrio vulnificus by API 20E. Overall, there were no differences between hyperpigmented and normal fish in terms of type or frequency of the isolates.

Following examination for up to $10 \mathrm{wk}$, no evidence of cytopathic effect was observed in any of the cell lines.

\section{Passive observation experiment}

Observations of dab representing the 3 categories held in aquarium facilities for 18 mo alongside normal fish did not show evidence of changes in the pattern of hyperpigmentation or development of pigment spots in the normal fish. However, overall colouration of the entire fish changed slightly according to season, hence the general appearance was lighter in the winter and darker during the summer months.
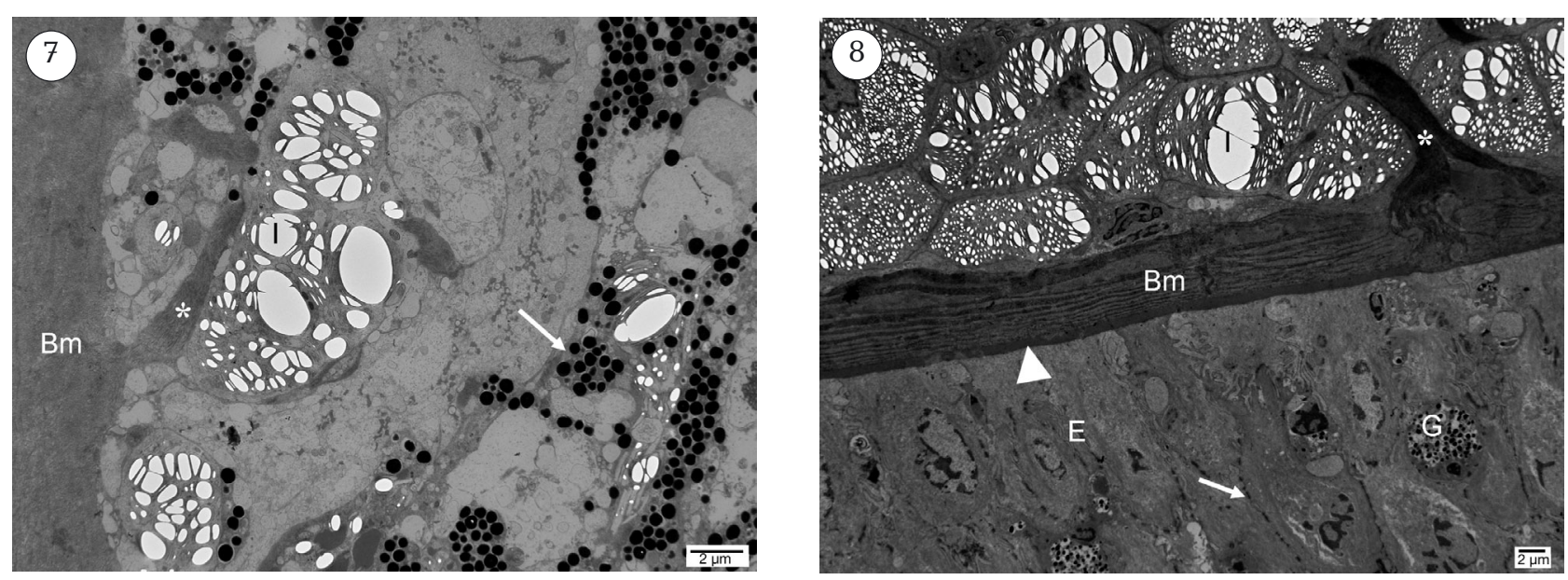

Figs. 7 \& 8. Limanda limanda. Ultrastructure of epidermal/dermal boundary of hyperpigmented dab (severity grade 3). Bm: basement membrane; I: iridophores; $*$ : anchoring fibrils. Scale bars $=2 \mu \mathrm{m}$. Fig. 7 . Ocular surface showing degenerate dermal cells interspersed with iridophores and numerous melanin granules (arrow). Degeneration is also evident in the anchoring fibrils of the basement membrane. Fig. 8. Abocular surface, showing intact epithelium, with tight cell-cell junctions (arrow), and containing occasional small granulocytes $(G)$. Proliferating iridophores are restricted to the dermal zone immediately underlying the basement membrane. Note intact basal lamina (triangle), and anchoring fibrils 
ported the macroscopically defined hyperpigmentation categories, showing differences between normally pigmented and hyperpigmented fish based on an altered pattern in the number and distribution of mostly normal chromatophores with no associated major pathological changes.

The colours and skin patterns recorded in teleosts are species-specific and determined by the neuralcrest-derived pigment cells (chromatophores) present in the dermal and epidermal skin layers (Schliwa 1986, Reedy et al. 1997, Bolker \& Hill 2000, Fukamachi et al. 2004). This ephemeral organ gives origin to undifferentiated precursor cells (chromatoblasts), which at later stages of development will migrate to the final location in the tegument, differentiating into 3 types of pigment cells: melanophores (dark brown and black colours), iridophores (reflective white or silvery patterns) and xanthophores (yellow to orange colours) (Schliwa 1986, Fujii 1993, Bolker \& Hill 2000, Bolker et al. 2005).

A change in fish body colouration is a phenomenon described as a response to 2 basic mechanisms: physiological or morphological colour changes (Schliwa 1986, Sugimoto 2002, Fukamachi et al. 2004). The first is attributed to rapid motile responses of chromatophores which actively re-distribute the pigment organelles (cells become more or less visible) and is mediated by nerve stimulation. These cytological adjustments are dynamic and reversible and can induce prompt and dramatic pigment changes (adaptive background colouration, signalling mood or physiological state), while the morphological mechanism results from pigment cell density or amount of pigment content variations and consequently is a much slower and lasting process (Schliwa 1986, Bolker \& Hill 2000, Burton 2010).

Data from this study, including the histological description and the long-term observational study, suggest that the abnormal pigmentation in common dab falls under a morphological colour change similar to that registered in the course of ontogeny, based on differentiation or disappearance of chromatoblasts (Bolker \& Hill 2000), and therefore is generally non-reversible. Adult fish skin contains factors that affect the function of pigment cells, and therefore, hyperpigmented areas of the skin could be the result of a localized expression of intrinsic melanisation stimulatory (MSF) or inhibitory factors (Zuasti 2002). MSF were originally described for the integument of channel catfish Ictalurus punctatus and later were also found in marine species (Zuasti et al. 1992, 1993, 2000). Our observations over a period of $18 \mathrm{mo}$ showed the stability of the fish colour patterns, con- firming the permanent nature of hyperpigmentation within the length range examined. We are aware that this observation might be biased, as a potential 'external factor' involved (such as environmental or stressing factors) might have been completely absent under laboratory conditions.

The chromatic asymmetry between the upper and lower side of flatfish has been described for several species (Burton 2010). The ability to vary pigment patterns in response to their environment is not uncommon, and the particular ability of flatfish to adjust their ocular side to match the substratum is widely described (Burton \& O'Driscoll 1992, Iwata \& Kikuchi 1998, Healey 1999, Bolker et al. 2005). However, this represents physiological colour changes based on local aggregations of melanosomes unmasking the dense clusters of iridophores, thus making them visible, versus melanosome dispersion within melanophores inducing a general darkening of the skin, which is likely what we observed during the winter and summer months of the passive observation study.

Black spots, viz. hyperplastic and neoplastic cutaneous lesions involving dermal chromatophores, are not uncommon in fish (Ozato \& Wakamatsu 1981, Masahito et al. 1989). However, among reported pigment abnormalities, ambicolouration (pigmentation on both ocular and abocular sides) and hypomelanosis (pseudoalbinism) are by far the most frequently reported anomalies with an associated economical impact (Harboe \& Adoff 2005, Hamre et al. 2007, Martinez et al. 2007). A neoplastic condition potentially associated with contaminants, such as that described for Pacific rockfish Sebastes spp. (Okhiro et al. 1993), is not suspected in the current work, as the hyperplasia observed did not involve an altered cell pattern. Similarly, a potential role of skinassociated parasites, such as those that occur with 'black spot disease' where a strong epidermal melanosis is induced by the host reaction to metacercaria (Kent \& Poppe 2002), was also ruled out based on the histological assessment, where no skin parasitic infection was observed in any of the fish analysed.

Under farming conditions, pigment abnormalities are believed to be primarily the result of a disrupted second phase of pigment development during metamorphosis, where a second wave of cell differentiation occurs and additional melanophores and the full complement of pigment cells develop, resulting in the final skin pattern of mature fish (Matsumoto \& Seikai 1992, Bolker et al. 2005). This suggests that colour pattern definition takes place at an early life stage and that, once established, the aberrant colour 
patterns are maintained through life. However, when Stentiford et al. (2010) investigated the age at first occurrence of several disease conditions affecting dab in the North Sea and the Irish Sea where the smallest fish sampled were in the range of 10 to $14 \mathrm{~cm}$ (the majority of these being 1 yr old), the first occurrence of hyperpigmentation in North Sea dab was found to be at 3 yr (Stentiford et al. 2010). Similarly, data from a different area of the North Sea recorded the first occurrence of hyperpigmentation in $2 \mathrm{yr}$ old dab, the smallest with $12 \mathrm{~cm}$ but higher prevalence observed in $>15 \mathrm{~cm}$ fish (Grütjen et al. 2013). These results together with our own data, where higher prevalence of hyperpigmentation was always observed in individuals greater than $\sim 15 \mathrm{~cm}$ (data not shown), suggest that the factors involved in the genesis of this condition must therefore be more complex.

While some ambicolouration such as that reported for Greenland halibut Reinhardtius hippoglossoides has been attributed to a genetic mutation (Burton 1988), a variety of colour abnormalities in flatfish have been largely and generally attributed to nutritional factors at early life stages, with vitamin A, fatty acids and thyroid hormones known to affect pigmentation (McEvoy et al. 1998, Hamre et al. 2007). Light wavelength also plays an important role, and fish skin is very susceptible to ultraviolet (UV) damage due the presence of living cells in all layers of the epidermis, the lack of a keratinized outer layer and of protective epidermal melanin-containing cells (Bullock et al. 1978, Bullock 1982). In this regard, however, common dab in our study showed some epidermal melanophores. These have been reported in common dab (Hewer 1927) as well as in other flatfish species, including European flounder Pleuronectes (= Platichthys) flesus (Cunningham \& MacMunn 1893), the Gulf flounder Paralichthys albiguttus (Kuntz 1915) and the winter flounder Pseudopleuronectes americanus (Burton 1988). Epidermal melanophores observed in our study were observed in normal and hyperpigmented fish, though more frequently in the latter. Their structure did not match that described for epidermal melanophores in other species (Obika \& Meyer-Rochow 1990, Ferrer et al. 1999), possessing thin dendritic processes with a 3-dimensional distribution between tightly compressed mid-epidermal cells (Burton 2010). In our study, the epidermal pigmented cells were mainly large clusters of melanincontaining cells which were morphologically very compact, with no dendritic formation and different from those in the dermal layer. The origin of epidermal melanophores has not been fully resolved; they could develop from other cells of the epidermis and are reported to be degenerating dermal melanophores in some teleosts (Stoumboudi et al. 2001), which could also be the case for flatfishes (Kuntz 1915, Hewer 1927); however, in our case they could also represent aggregates of migrated melanomacrophages, as they were seen in conjunction with a structurally distorted and infiltrated epidermal layer.

The thickening of the chromatophore dermal layer, namely melanophores, particularly in the upper skin surface of fish in grades 2 and 3 was a constant feature in the present study. Melanin pigmentation is known to be an effective sunscreen, and, in general terms, development of melanosis through light exposure is thought to be a protective reaction. In larvae of whitefish Coregonus spp. experimentally exposed to moderate UV-B radiation, 30\% more melanin was recorded in the skin compared to the non-exposed control group (Häkkinen et al. 2002). Data from our study, analysing grade 2 and 3 fish, and from other groups in different areas of the North Sea also suggest that the higher pigmented categories are more prevalent among larger fish (Grütjen et al. 2013). Interestingly however, the data suggest that higher pigmented fish have a lower condition factor (Grütjen et al. 2013).

None of the fish in our study was found to be free of some growth of bacteria from the skin, and a degree of lymphocytic infiltration was also observed. Although suggestive of an active immune response, allocating significance to these findings has to be balanced against the fact that lymphocytes can be present in normal fish skin epidermis (Roberts et al. 1972, Bullock \& Roberts 1974, Elliott 2000, Ferguson 2006), as also recorded in this study on some normal fish. A certain degree of infiltration might represent a relatively 'normal condition' for this bottom dweller, where even mild damage can lead to the release of cytokines and inflammatory reactions, a frequent observation in early superficial damage (Ferguson 2006).

At present we have no data regarding hyperpigmentation in juvenile or pelagic common dab, as the smallest fish we examined averaged $12 \mathrm{~cm}$ in length. As only young dab larvae are pelagic and live in the upper layers of the water column during the early spring and summer, they are likely to be impacted by UV-B radiation; however, after metamorphosis, young dab living in shallow waters such as the Wadden Sea will still be potentially exposed. If the influence of UV-B radiation at an early life stage, or a combination of light and nutritional factors, plays a role, then either the anomaly persists in a way that is 
enhanced with time/age, or abnormal pigmentation in larger fish also develops by other means, as discussed by Zuasti (2002) in relation to the influence of stimulatory or inhibitory molecules.

Hyperpigmentation in common dab shows an apparent increasing trend in areas of the North Sea (Grütjen et al. 2013) and clearly involves hyperplasia of dermal melanophores and iridophores. We found no evidence of specific association with microorganisms or parasites by light or electron microscopy or by standard bacteriological and virological assessment. The cause of hyperpigmentation in the common dab remains elusive, but ruling out the potential involvement of pathogens allows further research to focus on other, non-infectious, origins, including ontogeny disturbances, influence of UV radiation, nutrition, as well as environmental factors with the potential to disrupt or influence the normal function of the skin melanisation factors.

Acknowledgements. We appreciate the cooperation of the officers and crew of the RV 'Scotia III'. We also thank staff from the histology, virology and bacteriology laboratories for helping to process the samples. The support of the Department for Environment, Food and Rural Affairs contract SLA 24 (to S.W.F.) is gratefully acknowledged.

\section{LITERATURE CITED}

Bolker JA, Hill CR (2000) Pigmentation development in hatchery-reared flatfishes. J Fish Biol 56:1029-1052

Bolker JA, Hakala TF, Quist JE (2005) Pigmentation development, defects, and patterning in summer flounder (Paralichthys dentatus). Zoology 108:183-193

Bucke D, Vethaak AD, Lang T, Mellergaard S (1996) Common diseases and parasites of fish in the North Atlantic: training guide for identification. ICES techniques in marine environmental sciences no. 19. International Council for the Exploration of the Sea, Copenhagen

Bullock AM (1982) The pathological effects of ultraviolet radiation on the epidermis of teleost fish with reference to the solar radiation in higher animals. Proc R Soc Edinb 81:199-210

Bullock AM, Roberts RJ (1974) The dermatology of marine teleost fish. I. The normal integument. Oceanogr Mar Biol Annu Rev 13:383-411

> Bullock AM, Marks R, Roberts RJ (1978) The cell kinetics of teleost fish epidermis: mitotic activity of the normal epidermis at varying temperatures in plaice (Pleuronectes platessa). J Zool 184:423-428

Burton D (1988) Melanophore comparisons in different forms of ambicoloration in the flatfish Pseudopleuronectes americanus and Reinhardtius hippoglossoides. J Zool 214:353-360

Burton D (2010) Flatfish (pleuronectiformes) chromatic biology. Rev Fish Biol Fish 20:31-36

Burton D, O'Driscoll MP (1992) Facilitation of melanophore responses in winter flounder (Pseudopleuronectes americanus). J Exp Biol 168:289-299
Cunningham JT, MacMunn CA (1893) On the coloration of the skins of fishes, especially of Pleuronectidae. Philos Trans R Soc Lond B Biol Sci 184:765-812

Elliott DG (2000) Integumentary system. In: Ostrander GK (ed) The laboratory fish. Academic Press, London p 271-306

Ferguson HW (2006) Systemic pathology of fish. Scotian Press, London

> Ferrer C, Solano F, Zuasti A (1999) Ultrastructural and biochemical analysis of epidermal xanthophores and dermal chromatophores of the teleost Sparus aurata. Histol Histopathol 14:383-390

Fujii R (1993) Cytophysiology of fish chromatophores. Int Rev Cytol 143:191-255

Fukamachi S, Sugimoto M, Mitani H, Shima A (2004) Somatolactin selectively regulates proliferation and morphogenesis of neural-crest derived pigment cells in medaka. Proc Natl Acad Sci USA 101:10661-10666

Grütjen F, Lang T, Feist S, Bruno D, Noguera P, Wosniok W (2013) Hyperpigmentation in North Sea dab Limanda limanda. I. Spatial and temporal patterns and host effects. Dis Aquat Org 103:9-24

Gudger EW (1934) Ambicoloration in the winter flounder, Pseudopleuronectes americanus. Am Mus Novit 717:1-8

> Häkkinen J, Vehniäinen E, Ylönen O, Heikkilä J and others (2002) The effects of increasing UV-B radiation on pigmentation, growth and survival of coregonid embryos and larvae. Environ Biol Fishes 64:451-459

Hamre K, Holen E, Moren M (2007) Pigmentation and eye migration in Atlantic halibut (Hippoglossus hippoglossus L.) larvae: new findings and hypotheses. Aquacult Nutr 13:65-80

Harboe T, Adoff G (2005) Oppdrett av kveite. Kyst og Havbruk. In: Boxaspen K, Agnalt AL, Gjøsæter J, Jørgensen LL, Skiftesvik AB (eds) Fisken og havet, særnummer 2-2005. Institute of Marine Research, Bergen, p 123-126

$>$ Healey EG (1999) The skin pattern of young plaice and its rapid modification in response to graded changes in background tint and pattern. J Fish Biol 55:937-972

> Hewer HR (1927) Studies on the colour changes of fish. II. An analysis of the colour patterns of the dab. III. The action of nicotin and adrenalin in the dab. IV. The action of caffeine in the dab and a theory of the control of colour changes in fish. Philos Trans R Soc Lond B Biol Sci 215: $177-200$

Iwata N, Kikuchi K (1998) Effects of sandy substrate and light on hypermelanosis of the blind side in cultured Japanese flounder Paralichthys olivaceus. Environ Biol Fishes 52:291-297

Kent ML, Poppe TT (2002) Infectious diseases of coldwater fish in marine and brackish water. In: Woo PTK, Bruno DW, Lim LHS (eds) Diseases and disorders of finfish in cage culture. CABI Publishing, Wallingford, p 61-105

Kuntz A (1915) The histological basis of adaptive shades and color in the flounder Paralichthys albiguttus. Bull US Bur Fish 35:1-29

Lang T (2002) Fish disease surveys in environmental monitoring: the role of ICES. ICES Mar Sci Symp 215:202-212

Lang T, Wosniok W (2008) The Fish Disease Index: a method to assess wild fish disease data in the context of marine environmental monitoring. ICES CM 2008/D:01. International Council for the Exploration of the Sea, Copenhagen

Lyons BP, Thain JE, Stentiford GD, Hylland K, Davies IM, Vethaak AD (2010) Using biological effects tools to 
define good environmental status under the European Union marine strategy Framework Directive. Mar Pollut Bull 60:1647-1651

Martinez GM, Baron MP, Bolker JA (2007) Skeletal and pigmentation defects following retinoic acid exposure in larval summer flounder, Paralichthys dentatus. J World Aquacult Soc 38:353-366

Masahito P, Ishikawa T, Sugano H (1989) Pigment cells and pigment cell tumors in fish. J Invest Dermatol 92: 266S-270S

Matsumoto J, Seikai T (1992) Asymmetric pigmentation and pigment disorders in Pleuronectiformes (flounders). Pigm Cell Res 3(Suppl 2):275-282

McEvoy LA, Næss T, Bell JG, Lie $\varnothing ~(1998)$ Lipid and fatty acid composition of normal and malpigmented Atlantic halibut (Hippoglossus hippoglossus) fed enriched Artemia: a comparison with fry fed wild copepods. Aquaculture 163:237-250

McVicar AH, Bruno DW, Fraser CO (1988) Fish disease in the North Sea in relation to sewage sludge dumping. Mar Pollut Bull 19:169-173

Obika M, Meyer-Rochow VB (1990) Dermal and epidermal chromatophores of the Antarctic teleost Trematomus bernacchii. Pigm Cell Res 3:33-37

Okhiro MS, Whipple JA, Froff JM, Hinton DE (1993) Chromatophoromas and chromatophore hyperplasia in $\mathrm{Pa}-$ cific rockfish (Sebastes spp.). Cancer Res 53:1791-1793

Ozato K, Wakamatsu Y (1981) Age-specific incidence of hereditary melanomas in the Xiphophorus fish hybrids. Carcinogenesis 2:129-133

Reedy MV, Parichy DM, Erickson CA, Mason KA, FrostMason SK (1997) The regulation of melanoblast migration and differentiation. In: Nordlund JJ, Boissy RE, Hearing VJ, King RA, Ortonne JP (eds) The pigmentory system and its disorders. Oxford University Press, Oxford, p 75-95

Editorial responsibility: Bernd Sures, Essen, Germany
Roberts RJ, Young H, Milne JA (1972) Studies on the skin of plaice (Pleuronectes platessa L). 1. The structure and ultrastructure of normal plaice skin. J Fish Biol 4: 87-98

Schliwa M (1986) Pigment cells. In: Bereiter-Hahn J, Matoltsy G, Richards KS (eds) Biology of the integument, Vol 2: Vertebrates. Springer-Verlag, Berlin, p 65-77

Stentiford GD, Bignell JP, Lyons BP, Feist SW (2009) Sitespecific disease profiles in fish and their use in environmental monitoring. Mar Ecol Prog Ser 381:1-15

Stentiford GD, Bignell JP, Lyons BP, Thain JE, Feist SW (2010) Effect of age on liver pathology and other diseases in flatfish: implications for assessment of marine ecological health status. Mar Ecol Prog Ser 411:215-230

Stoumboudi MT, Abraham M, Wendelaar BSE, Iger Y, Tsangavis $K$, van Ham E, Alexis M (2001) Ammonia induces stress-related changes in the skin of cultured gilthead seabream. Abstracts. 10th European Congress of Ichthyology, Prague, 3-7 September 2001, p 31

Sugimoto M (2002) Morphological color changes in fish: regulation of pigment cell density and morphology. Microsc Res Tech 58:496-503

Zuasti A (2002) Melanization stimulating factor (MSF) and melanization inhibiting factor (MIF) in the integument of fish. Microsc Res Tech 58:488-495

Zuasti A, Johnson WC, Samaraweera P, Bagnara JT (1992) Intrinsic pigment cell stimulating activity in the catfish integument. Pigm Cell Res 5:253-262

Zuasti A, Martínez-Liarte JH, Ferrer C, Cañizares M, Newton J, Bagnara JT (1993) Melanization stimulating activity in the skin of the gilthead porgy, Sparus auratus. Pigm Cell Res 6:359-364

> Zuasti A, Martínez-Liarte JH, Solano F, Ferrer C (2000) Melanization stimulating factors in the integument of the Mugil cephalus and Dicertranchus labrax. Histol Histopathol 15:1145-1150

Submitted: May 2, 2012; Accepted: October 31, 2012 Proofs received from author(s): February 13, 2013 